Research report

\title{
Electrophysiological alterations in a complex rat model of schizophrenia
}

\author{
Gyongyi Horvath ${ }^{\mathrm{a}, *}$, Zita Petrovszki ${ }^{\mathrm{b}}$, Gabriella Kekesi $^{\mathrm{a}}$, Gabor Tuboly $^{\mathrm{c}}$, Balazs Bodosi ${ }^{\mathrm{a}}$, \\ Janos Horvath $^{\mathrm{a}}$, Peter Gombkötö ${ }^{\mathrm{a}}$, Gyorgy Benedek ${ }^{\mathrm{a}}$, Attila Nagy ${ }^{\mathrm{a}}$ \\ a Department of Physiology, Faculty of Medicine, University of Szeged, Dóm tér 10., H-6720 Szeged, Hungary \\ b Institute of Physical Education and Sport Medicine, Juhász Gyula Faculty of Education, University of Szeged, Hattyas sor 10., H-6725 Szeged, Hungary \\ ' Department of Neurology, Faculty of Medicine, University of Szeged, Semmelweis u. 6., H-6720 Szeged, Hungary
}

\section{H I G H L I G H T S}

- EEG phenotype characterization in a rat substrain related to schizophrenia/autism.

- ERPs showed significant changes in P2 latency and N1 amplitude.

- Acute ketamine treatment did not cause alterations in ERPs.

- Altered power of oscillations in different frequency bands was observed.

- Ketamine caused strain-dependent changes in the power of oscillations.

\section{A R T I C L E I N F O}

\section{Article history:}

Received 18 December 2015

Received in revised form 25 March 2016

Accepted 29 March 2016

Available online 30 March 2016

\section{Keywords:}

Autism

Event related potentials

Neuronal oscillation

Power spectrum analysis

Rat model

Schizophrenia

\begin{abstract}
A B S T R A C T
Background: Psychiatric disorders are frequently accompanied by changes in brain electrical oscillations and abnormal auditory event related potentials. The goal of this study was to characterize these parameters of a new rat substrain showing several alterations related to schizophrenia.

Methods: Male rats of the new substrain, developed by selective breeding after combined subchronic ketamine treatment and postweaning social isolation, and naive Wistar ones group-housed without any interventions were involved in the present study. At the age of 3 months, animals were implanted with cortical electroencephalography electrodes. Auditory evoked potentials during paired-click stimuli and power of oscillation in different frequency bands were determined with and without acute ketamine $(20 \mathrm{mg} / \mathrm{kg})$ treatment.

Results: Regarding the auditory evoked potentials, the latency of P2 was delayed and the amplitude of N1 peak was lower in the new substrain. The new substrain showed increased power of oscillations in the theta, alpha and beta bands, while decreased power was detected in delta and gamma2 bands $(52-70 \mathrm{~Hz})$ compared with control animals. Acute ketamine treatment increased the gamma1 band $(30-48 \mathrm{~Hz})$ power in both groups, while it elicited significant changes only in the new substrain in the total power and in alpha, beta and gamma 2 bands.

Conclusions: The validation of the translational utility of this new rat substrain by electrophysiological investigations revealed that these rats show abnormalities that may model a part of the neurophysiological deficits observed in schizophrenia.
\end{abstract}

(C) 2016 Elsevier B.V. All rights reserved.

\footnotetext{
Abbreviations: EEG, electroencephalography; ERP, event related potential; NMDAR, $N$-methyl-D-aspartate receptor.

* Corresponding author.

E-mail addresses: horvath.gyongyi@med.u-szeged.hu (G. Horvath), petrovszki.zita@med.u-szeged.hu (Z. Petrovszki), kekesi.gabriella@med.u-szeged.hu (G. Kekesi),

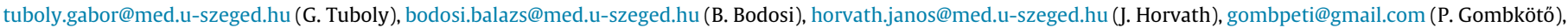
benedek.gyorgy@med.u-szeged.hu (G. Benedek),nagy.attila.1@med.u-szeged.hu (A. Nagy).
} 


\section{Introduction}

Schizophrenia is a common neurodevelopmental and highly heritable neuropsychiatric disorder [1,2]. Over the past few decades, researches using electroencephalography (EEG) have identified several neurophysiological alterations in this disease, indicating neural circuit disruptions. Unfortunately, the results are controversial, and they may depend on the subtype or phase of the disease; therefore, its modeling in preclinical research field is a big challenge [3-9]. It is argued that perfect simulation of inherently human diseases in animals might be impossible, but the recreation of endophenotypes related to the disorders is a possibility. Therefore, developing animal models with abnormal EEG activity may help in the clarification of the mechanisms in the background of this neuropsychiatric disease $[10,11]$. Previous studies using different rodent models of schizophrenia showed widely diversified alterations in the power of EEG oscillations and event related potentials (ERP) [12-23].

Preclinical and clinical studies focusing on pharmacological and genomical changes support the hypothesis that hypofunction of $\mathrm{N}$ methyl-D-aspartate receptor (NMDAR) signaling contributes to the pathophysiology of schizophrenia; therefore, NMDAR antagonists, including ketamine, have been used extensively to probe questions related to its neurobiology [24-28]. Ketamine administered to healthy controls in subanesthetic dose mimics several symptoms of schizophrenia, and it worsens these signs in schizophrenia patients $[24,29,30]$. Furthermore, NMDAR antagonists or silencing of these receptors are used in animal models of neuropsychiatric disorders showing several alterations in EEG activity, too [13,18,25,31-34].

We developed a complex animal model by selective breeding based on behavioral alterations after combined subchronic ketamine treatment and postweaning social isolation [35,36]. It is thought that selective breeding for phenotypic extremes increases the homozygosity of genes that affect the selected trait, whereby the allelic frequency of trait-irrelevant genes remains unaffected [37]. Therefore, animals selectively bred for a behavioral given phenotype are increasingly used to study pathophysiological mechanisms underlying certain disorders. For example, rats have been successfully bred for anxiety [38], reduced sensorimotor gating [39] and for seizure susceptibility [40]. Several aspects of schizophrenia were found in the new substrain, i.e., disturbances in pain sensitivity, sensory gating, memory functions, motor activity and stereotypic behaviors [35,36]. Our recent data indicated that both heritable and environmental factors (i.e., juvenile social isolation and ketamine treatment) are important in the generation of the behavioral alterations, but the most significant changes were observed after the combination of treatments with selective breeding $[35,36,41]$. In order to keep the number of animals used in the experiments at minimal level, we decided to compare two groups of animals, i.e., naive rats without any intervention and the new substrain after juvenile isolation and subchronic ketamine treatment. In this report, the electrophysiological phenotype of this new rat substrain was characterized by the investigation of ERPs, their gating, and the basal frequency bands with and without acute ketamine treatment, to test the potential usefulness of the substrain in studying the neurophysiological deficits related to schizophrenia.

\section{Methods}

All experiments involving animal subjects were carried out with the approval of the Hungarian Ethics Committee for Animal Research (registration number: XIV/03285/2011). Animal suffering and the number of animals per group were kept to a minimum.

\subsection{Selective breeding process}

The paradigm for selective breeding was described previously $[35,36]$. Briefly, the parental generation consisted of male and female (10-10) outbred Wistar rats. Offsprings of the rats in the next generations were tested after weaning with the tail-flick test $\left(48^{\circ} \mathrm{C}\right.$ hot water) to assess pain sensitivity, and then housed individually for 28 days. The animals were treated with ketamine (Calypsol, Richter Gedeon Plc., Budapest, Hungary; $30 \mathrm{mg} / \mathrm{kg}$ IP, $4 \mathrm{~mL} / \mathrm{kg}$, daily, 5 times/week, 15 injections in total) from 5 to 7 weeks of age. Then the animals were re-housed (4-5 rats/cage) and 1 week of recovery was provided to them with no treatment. Starting at the age of 9 weeks, the pain sensitivity, the sensory gating with prepulse inhibition, and the cognitive functions and stereotypic behavior on novel object cognition test were assessed (Table 1 ). Animals ( 5 male with 10 female) with the highest level of disturbances in these parameters were used for selective breeding throughout several generations.

\subsection{Experimental paradigm for EEG experiments}

Two experimental groups of 8-8 rats were compared: naive socialized male rats without any interventions; and the 17th generation of selectively bred male rats with social isolation and ketamine treatment as new substrain. After the above-mentioned behavioral tests, the animals were involved in the EEG experiments (Table 1).

Rats were anesthetized with a mixture of ketamine hydrochloride and xylazine ( 72 and $8 \mathrm{mg} / \mathrm{kg}$ intraperitoneally, respectively), and transferred into a stereotaxic frame. Afterwards, small burr holes were drilled in their skull for electrode placement according to coordinates found in the rat brain atlas [42]. The target area for the epidural stainless steel electrodes and coordinates relative to bregma were the following at both sides: recording electrodes: parietal cortex $6 \mathrm{~mm}$ posterior, $2 \mathrm{~mm}$ lateral to bregma; reference electrodes: $1.5 \mathrm{~mm}$ posterior to bregma, $2 \mathrm{~mm}$ lateral, and a ground electrode $2.5 \mathrm{~mm}$ posterior to bregma, $1 \mathrm{~mm}$ lateral. Finally, electrodes were placed in a miniature 6-pin connector, which was fixed with dental cement.

After the surgery, the animals were injected with gentamycin ( $10 \mathrm{mg} / \mathrm{kg}$, subcutaneously) to prevent infection, and were housed individually. They were allowed to recover for one week with a 12:12-h light-dark cycle, an ambient temperature regulated at $23^{\circ} \mathrm{C}$, water and food with ad libitum access.

On the testing days (between 8:00 AM and 12:00 PM), animals were placed in the recording chamber $(\mathrm{L}: 34 \mathrm{~cm}, \mathrm{~W}: 14.5 \mathrm{~cm}, \mathrm{H}$ : $33.5 \mathrm{~cm}$ ), recording cables were attached to commutators allowing the free movement of the rats, and they were allowed to accommodate to the test environment for $10 \mathrm{~min}$ while auditory stimuli were not present.

Following the acclimatization, the 20 min test session was initiated. For generation of ERPs to the sensory gating paradigm, two consecutive clicks ( $70 \mathrm{~dB}$ clicks with broad spectrum for $5 \mathrm{~ms}$ : S1 and S2) were presented with interstimulus interval of $500 \mathrm{~ms}$. The interval between the pairs of clicks was $5 \mathrm{~s}$. Clicks were driven by a computer program and delivered via loudspeakers.

To habituate the animals to the task and to minimize the potential discomfort during the tests, three recording sessions were performed on three consecutive weeks without any intervention. Then EEG recordings were repeated after acute ketamine $(20 \mathrm{mg} / \mathrm{kg}$ intraperitoneally) or vehicle (saline) injection on the subsequent two weeks. Each animal was given both injections with 7 days apart, and the order of vehicle and drug administration was counterbalanced. After the injections, the rats were placed in their cage for 20 min before putting them to the recording chamber for EEG registration. 
Table 1

Experimental paradigm.

\begin{tabular}{|c|c|c|c|c|c|c|c|c|c|}
\hline \multirow[t]{2}{*}{ Groups } & \multicolumn{9}{|l|}{ Age (weeks) } \\
\hline & 3 & 4 & $5-7$ & 8 & 9 & 10 & 12 & $13-15$ & $16-17$ \\
\hline $\begin{array}{l}\text { Naive rats } \\
\quad(n=8) \\
\text { New } \\
\text { substrain } \\
(n=8)\end{array}$ & $\begin{array}{l}(\text { PD21) } \\
\text { weaning TF } \\
\text { test } 1\end{array}$ & $\begin{array}{l}\text { group } \\
\text { housing } \\
\text { social } \\
\text { isolation }\end{array}$ & $\begin{array}{l}\text { social isola- } \\
\text { tion + ketamine } \\
\text { treatment }\end{array}$ & $\begin{array}{l}\text { group } \\
\text { housing }\end{array}$ & $\begin{array}{l}\text { TF test } 2 \\
\text { PPI test }\end{array}$ & NOR test & $\begin{array}{l}\text { EEG } \\
\text { electrode } \\
\text { implanta- } \\
\text { tion + recovery } \\
\text { (7 days) }\end{array}$ & $\begin{array}{l}\text { EEG for } \\
\text { habituation }\end{array}$ & $\begin{array}{l}\text { EEG } \\
\text { registration } \\
\text { after acute } \\
\text { ketamine/salin } \\
\text { treatment }\end{array}$ \\
\hline
\end{tabular}

Abbreviations: PD-postnatal day; TF-tail-flick; PPI-prepulse inhibition; NOR-novel object recognition; EEG-electroencephalogram.

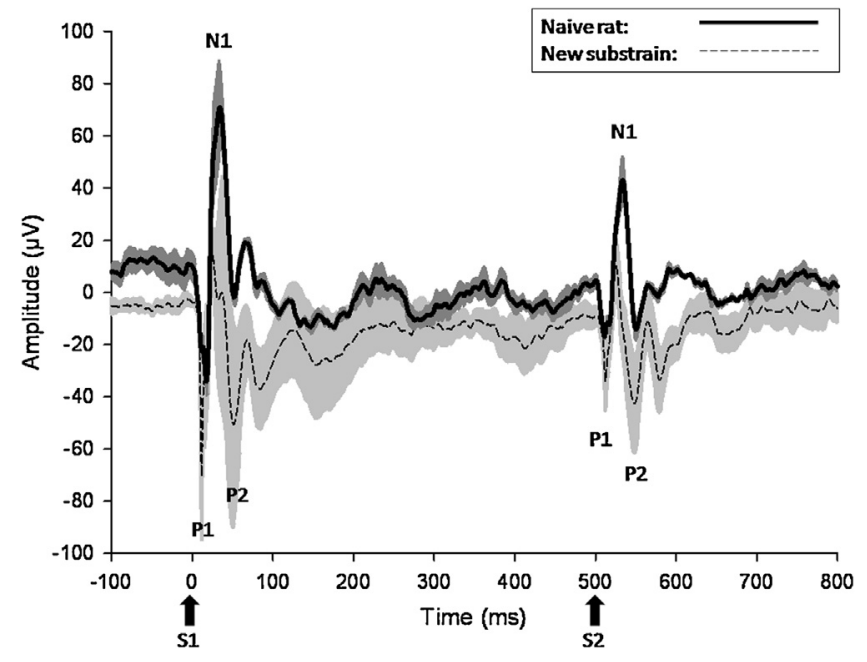

Fig. 1. Event related potentials (ERPs) using the paired-click paradigm.

Average of ERPs with SEM in naive and new substrain rats in response to the first (S1) and the second (S2) auditory stimuli. Arrows denote stimulus onsets. P1, N1 and $\mathrm{P} 2$ refer to ERP-related peaks.

Bipolar EEG recordings were performed from both sides of the skull. The signals were amplified with a custom made eight channel EEG amplifier (gain setting: 1000) by using AD8222 (Analog Devices Inc.) high performance instrumentation amplifier. The signals were online filtered using the following filter settings: high pass filter $=0.33 \mathrm{~Hz}$; low pass filter $=155 \mathrm{~Hz}$. The amplified and filtered signals were then digitized and recorded with a 16 channel Datawave system. The sampling rate of the electrophysiological signals was $5 \mathrm{kHz}$. The recorded EEG signals were stored on a computer for subsequent offline analysis.

\subsection{Data analysis}

We calculated the averaged ERP in response to S1 and S2 to measure the amplitudes, latencies of the responses and their gating.

The P1, N1 and P2 components were identified accordingly: P1 was the first positive-going wave that occurs in the range of 10-45 ms after stimulus, the N1 component was the first negativegoing component directly following P1 in the range of $20-70 \mathrm{~ms}$ after stimulus, and P2 was the second positive-going wave that occurs between 40 and $100 \mathrm{~ms}$ (Fig. 1). The amplitudes and the latencies of each component were determined. Gating was defined as the ratio of the peak-to-peak amplitudes of the corresponding components recorded as the first and second ERPs. Therefore, two segments were calculated: the difference between P1 and N1 and between $\mathrm{N} 1$ and $\mathrm{P} 2$, and the magnitude of inhibition was defined as the ratio of the evoked responses (S2/S1) for both amplitudes (G1 and G2).

Power density values were calculated by fast Fourier transformation (FFT) of artefact-free epochs under condition of $0.61 \mathrm{~Hz}$ resolution with a Hanning window for 5 min peri- ods before the auditory stimuli in the frequency range of delta $(0.6-4 \mathrm{~Hz})$, theta $(4-8 \mathrm{~Hz})$, alpha $(8-13 \mathrm{~Hz})$, beta $(13-30 \mathrm{~Hz})$ and gamma $1(30-48 \mathrm{~Hz})$, gamma $(52-70 \mathrm{~Hz})$ and gamma 3 $(71-100 \mathrm{~Hz})$ bins/waves. Relative band powers were expressed as power ratios of each frequency band to the total (z-score).

The obtained EEG data were analyzed off-line with Datawave system (DataWave Technologies, Loveland, CO, USA) and Spike2 (Cambridge Electronic Design, Cambridge, UK) systems. Data are expressed as means \pm SEM. Mean values of the different parameters were compared with ANOVA, with factors group, clicks and treatment. When the global test was significant, the LSD post hoc test was used for the evaluation of the effects of the various parameters. Statistical analysis was performed with Statistica 11.0 software (Statsoft, Tulsa, Oklahoma, USA). Differences were considered significant for $\mathrm{p}<0.05$.

\section{Results}

\subsection{Behavioral alterations}

In agreement with our recent studies [35,36], the naive and new substrain rats involved in the EEG experiments showed significant differences on the behavioral tests. Thus, the new substrain showed blunted pain sensitivity detected at the age of 3 and 9 weeks: ANOVA revealed significant effects of group $\left(\mathrm{F}_{(1,14)}=12.53\right.$; $\mathrm{p}<0.05)$ and time $\left(\mathrm{F}_{(1,14)}=87.20 ; \mathrm{p}<0.0001\right)$ with significantly longer latencies in the new substrain at week 9. Impaired sensory gating on the prepulse-inhibition test was also present: ANOVA revealed a significant effect of group $\left(F_{(1,14)}=5.99 ; p<0.05\right)$ with lower values in the new substrain. ANOVA showed that the new substrain spent significantly less time with the exploration of the new object compared to the naive ones $\left(F_{(1,14)}=11.73\right.$, $\mathrm{p}<0.005)$ in the novel object recognition test. Furthermore, the grooming activity of the new substrain was significantly higher $\left(F_{(1,14)}=5.92, p<0.05\right)$ that was accompanied by lower rearing activity $\left(\mathrm{F}_{(1,14)}=10.71, \mathrm{p}<0.01\right)$.

Qualitative observations indicated that the rats had mild impairments in coordination and locomotor activity following acute ketamine treatment during the EEG recordings.

\subsection{Analysis of ERP responses}

Regarding the latency of $\mathrm{P} 1$ and N1 peaks, there were no significant differences between the groups, the treatments, the first and second clicks and their interactions (data are not shown). Regarding the latency of P2, ANOVA showed a significant effect of group $\left(F_{(1,28)}=14.99 ; p<0.001\right)$, thus the new substrain had longer latencies compared to the control group, but neither ketamine treatment nor the order of the clicks influenced it (Fig. 2A).

The second click induced lower amplitudes of all the peaks compared to the first one in both groups, and this decrease was not influenced by acute ketamine treatment. Regarding the differences between the two groups for both clicks no significant differences were observed in the amplitude of P1 and P2 peaks (data are not 

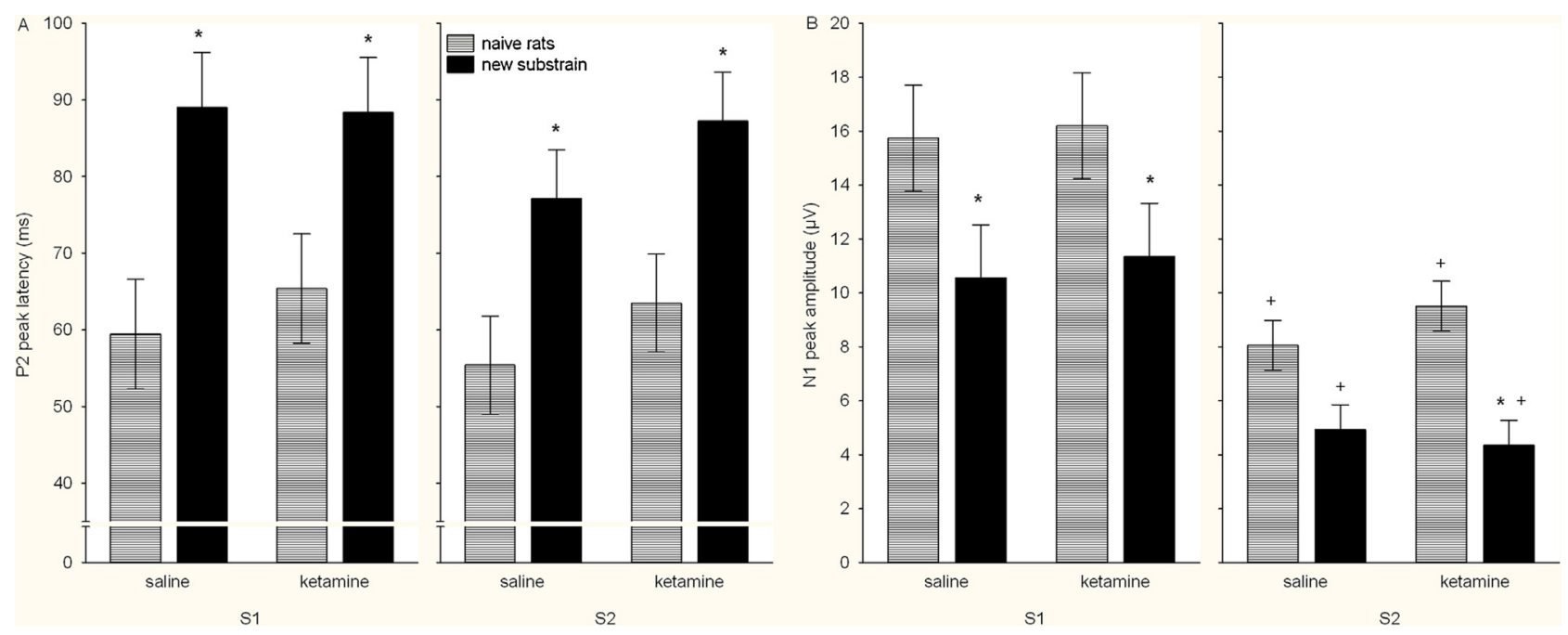

Fig. 2. Alterations in the peaks of event related potentials.

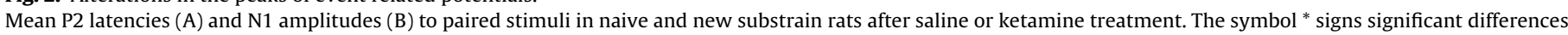
compared to naive group. The symbol + denotes significant differences between responses to S1 and S2 stimuli.

shown), but N1 peak was significantly lower in the new substrain compared to the control one; thus, ANOVA showed a significant effect of group $\left(\mathrm{F}_{(1,28)}=11.44 ; \mathrm{p}<0.005\right)$ (Fig. 2B).

As regards the degree of gating there was no significant difference between the two groups in the G1 value (G1 naive: $0.53 \pm 0.03$ vs. G1 new substrain: $0.51 \pm 0.09$ ), while $G 2$ was higher in the control group, thus the degree of the gating was lower in these animals (G2 naive: $0.63 \pm 0.04$ vs. G2 new substrain: $0.49 \pm 0.03$; $\mathrm{p}<0.05$ ). Acute ketamine treatment had no significant influence on these parameters (G1 naive $0.55 \pm 0.03$ vs. $G 1$ new substrain $0.42 \pm 0.05$; and G2 naive: $0.52 \pm 0.04$ vs. G2 new substrain: $0.48 \pm 0.04$ ).

\subsection{Oscillatory activity}

As regards the total power of the waves, ANOVA showed a significant effect of group $\left(\mathrm{F}_{(1,28)}=9.15 ; \mathrm{p}<0.01\right)$. Post-hoc test revealed that the new substrain had significantly higher total power after ketamine treatment compared to the control animals (Fig. 3A).

Regarding the delta band, ANOVA showed a significant effect of group $\left(\mathrm{F}_{(1,28)}=8.84 ; \mathrm{p}<0.01\right)$; thus, the new substrain had lower power in this frequency band, while ketamine did not influence significantly this parameter in either group (Fig. 3B).

As regards the theta band, ANOVA showed a significant effect of group $\left(\mathrm{F}_{(1,28)}=6.12 ; \mathrm{p}<0.05\right.$; alpha); therefore, the new substrain had higher power in this frequency band without ketamine treatment, but ketamine decreased the differences between the two groups (Fig. 3B).

As regards the alpha band, ANOVA showed a significant effect of group $\left(\mathrm{F}_{(1,28)}=4.89 ; \mathrm{p}<0.05\right)$ and treatment $\left(\mathrm{F}_{(1,28)}=8.37 ; \mathrm{p}<0.01\right)$; thus, the new substrain had higher power in this frequency band that was significantly decreased by acute ketamine treatment (Fig. 3C).

As regards the beta band, ANOVA showed a significant effect of treatment $\left(\mathrm{F}_{(1,28)}=10.41 ; \mathrm{p}<0.005\right)$ and the group and treatment interaction $\left(\mathrm{F}_{(1,28)}=5.21 ; \mathrm{p}<0.05\right)$; therefore, the new substrain had higher power in this frequency band that was significantly decreased by acute ketamine treatment similarly to alpha band (Fig. 3C).

As regards the gamma1 band, ANOVA showed a significant effect of treatment $\left(\mathrm{F}_{(1,28)}=11.81 ; \mathrm{p}<0.005\right)$, thus, acute ketamine injection significantly increased the power of this band in both groups (Fig. 3D).
As regards the gamma2 band, ANOVA showed a significant effect of treatment $\left(\mathrm{F}_{(1,28)}=5.45 ; \mathrm{p}<0.05\right)$ and the group and treatment interaction $\left(\mathrm{F}_{(1,28)}=6.22 ; \mathrm{p}<0.05\right)$; therefore, the new substrain had lower power in this frequency band that was significantly increased by acute ketamine treatment (Fig. 3D). As regards the gamma3 waves, no significant effects were observed (Fig. 3D).

\section{Discussion}

The electrophysiological validation of the translational utility of this new rat substrain revealed that these animals showed several neurophysiological abnormalities observed in schizophrenia. The latency of the $\mathrm{P} 2$ peaks was prolonged, and the amplitude of $\mathrm{N} 1$ response decreased; however, the gating was not impaired in these animals in the double-click paradigm. Furthermore, the acute treatment with a subanesthetic dose of ketamine did not result in significant alterations in ERP parameters. The new substrain showed increased power of oscillations in the theta, alpha and beta ranges, while decreased power was detected in delta and gamma2 bands compared with the control animals. Ketamine treatment increased the gamma1 band power in both groups, while it caused significant changes only in the new substrain in the total power and in alpha, beta and gamma2 bands, suggesting the enhanced sensitivity for this drug.

Paired-click paradigm is a standard method used to assess sensory gating [43]. ERP in human studies has a positive deflection occurring approximately $50 \mathrm{~ms}$ following the onset of sensory stimulation (P50), which is generated primarily in the auditory thalamus and temporal cortex $[44,45]$. The N100 component, a large negative deflection, occurs following the P50 response originated mainly from the primary auditory cortex [46]. The second positive deflection that emerges approximately $200 \mathrm{~ms}$ after sensory stimulation (P200) is generated by the association cortex reflecting higher-order integration and interpretation of sensory stimuli. The ERP waveforms obtained in rodents show very similar characteristics to human ones with the exception that the latencies of the rodent ERP are significantly shorter [4]. Thus, ERPs in rodent typically show a positive deflection between 10 and $30 \mathrm{~ms}$ (P1), a negative deflection between 30 and $50 \mathrm{~ms}$ (N1), and a second positive deflection between 50 and $100 \mathrm{~ms}$ (P2) (Fig. 1).

Reduced peak amplitudes of the auditory ERP are well replicated in schizophrenic patients [43,45,46], and have been observed in multiple relevant rodent models [19], but no changes in 

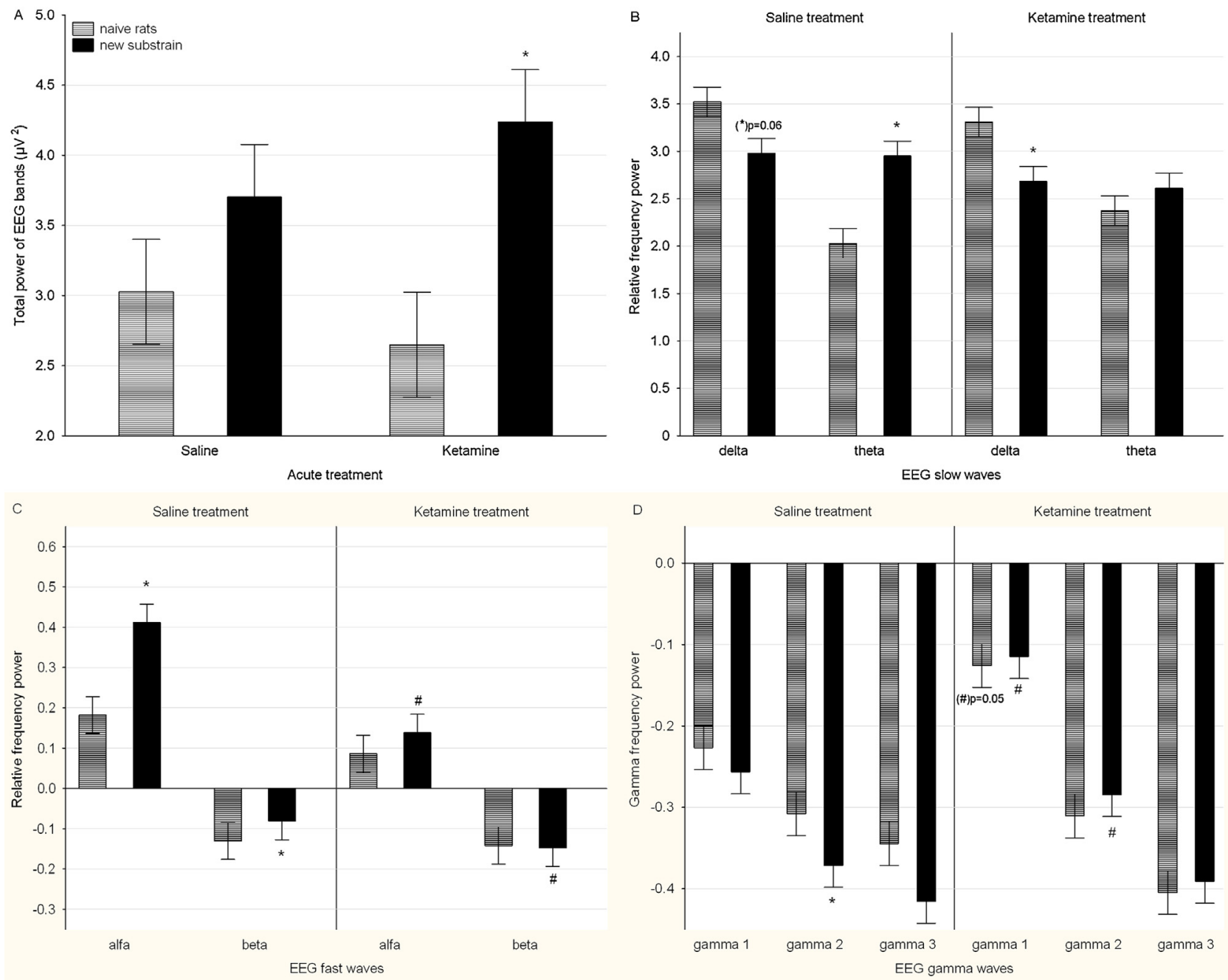

Fig. 3. Basal EEG power in different frequency bands.

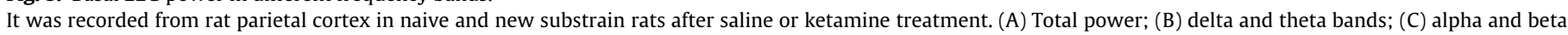

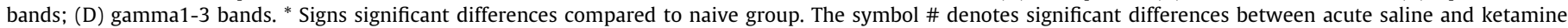
treatments.

these parameters were also reported $[44,46]$. Ketamine exposure decreased the amplitude of ERP in several human and animal studies $[12,21,34,46,47]$, but contradictory results are also available [48]; the latter is in agreement with our results. It seems that the P50 responses have limited utilities as a clinical or research tool; however, reduction in N100 amplitude is widely reported in schizophrenia as an endophenotype with a strong heritability, representing deficits in initial sensory processing and early attention [46]. Therefore, the change in N1 peak amplitude in rodents may be a potential biomarker for schizophrenia that has been detected in disease-relevant transgenic mice and also induced by acute ketamine treatment $[43,46,48]$. The decreased N1 response, observed in our substrain, is in agreement with these studies, which suggests that this substrain may simulate schizophrenia in this respect. Amplitude of the P200/P2 is reduced in schizophrenia, after acute exposure to ketamine in healthy controls and rodents, however, we did not detect it in our substrain, which might be due to the differences in the applied dose or the strain [46].

EEG recordings in healthy humans exhibit habituation to repeated stimuli; thus the amplitude of the auditory evoked potential is markedly attenuated upon the second click stimulus compared with the first one $[5,44,45]$. The sensory gating paradigm has been frequently used to study neurophysiological processes in schizophrenia, however, ERP-based sensory gating findings in this disease are somehow diverse; several studies show deficits $[4,45,46,49,50]$, while some are negative, as it was found in the new substrain [51-53]. The ineffectivity of both acute and chronic ketamine treatment on the ERP gating, in agreement with our data, indicates that NMDA receptors may not be critically involved in its generation [12,47,54-56]. Altogether, the alterations observed in the ERPs in our substrain showed limited correlation with the human schizophrenic data (decreased amplitude of N1).

Several neural oscillatory abnormalities have been demonstrated in schizophrenia that may contribute to the abnormal sensory and cognitive performance $[1,3,7-9,46,57,58]$. Neural oscillations depend on the kinetics of inhibitory (GABAergic) and excitatory (glutamatergic) synaptic interactions, and the ineffective inhibitory control of sensory processing is characteristic in this disease [3,16,17,47,59-61]. Because of the prominent role of gamma-band activity in cognition during normal brain functioning, there has been a particular focus on the investigation of high-frequency activity in patient populations [46]. Fast-spiking, parvalbumin-positive GABAergic neurons play a pivotal role in the primary generation of high-frequency oscillations and their synchronization, whereas glutamatergic pyramidal neurons appear to control their strength, duration, and long-range synchronization acting primarily via NMDARs [3,18,32,46,59,61]. Many human studies observed reduced gamma oscillatory activity, which may 
reflect the deficits in cognitive and sensory processing related to negative symptoms in schizophrenia [3,47,57,62,63]. However, there are controversial finding of increased gamma activities in schizophrenia as well, and it is reportedly relevant to positive symptoms (hallucination, delusion) [9,25,64-67]. Abnormal gamma activity has been reported in numerous animal models of schizophrenia, too, e.g., silencing of the GABAergic interneurons and hypofunction of NMDAR signaling is accompanied by altered oscillatory power particularly in the gamma range $[17,32,46,68]$. Chronic NMDAR antagonist treatment may cause decreased oscillatory power several weeks or months after the cessation of the treatment, suggesting long-lasting consequences of such an intervention $[12,21,69]$. Thus, the decreased gamma power between 52 and $70 \mathrm{~Hz}$ in our new substrain might be due, at least partially, to chronic ketamine treatment. Regarding the acute drug effect, in agreement with our results, significantly elevated gamma band oscillations have been observed in both human and animal studies, reflecting a cortical hyperglutamatergic state through GABAergic disinhibition, leading to a mild shift in the excitation/inhibition balance toward excitation [12,16,47,58,70-73].

Beta oscillations, less explored in schizophrenia, are believed to be generated broadly across multiple neocortical structures and are involved in the adaptation to repetitive sensory stimuli, attention, and synchronization of large ensembles of neurons $[3,46]$. In agreement with results observed in the new substrain, beta band power increases in patients with schizophrenia, which may be due to global cortical hyperexcitability or attention disturbances observed in these patients [74]. As regards the alpha band oscillation, it is related primarily to the thalamus; thus, the alterations in this frequency band may suggest dysfunction of the inhibitory thalamic neurons $[74,75]$. Different laboratories have reported either higher alpha power associated with negative symptoms $[46,66,74]$ or reduced alpha band power in a phase-independent manner $[46,74]$, thus the enhanced power observed in our new substrain might be related to the negative symptoms of schizophrenia.

Abnormalities in lower frequency oscillations (delta and theta) are also prominent in this disease $[7,8,76,77]$. The cortical delta band oscillation originates from the reticular nucleus of the thalamus, where predominantly parvalbumin-positive GABAergic neurons are present [78]. They can be partially but tonically activated via NMDARs, thereby regulating the activity of thalamic relay neurons projecting to the prefrontal cortex. The theta frequency range is associated with cognition/memory function, where cortico-hippocampal circuits are key generators of the rhythm [59]. Both delta and theta band changes depend on the phase of schizophrenia, i.e., patients with positive signs show nochanges or decrease in these parameters, while in negative phase of schizophrenia increases were detected [25,65,66,74,77]. Our model showed decreased delta activity, which might simulate the positive phase of schizophrenia, while the enhanced theta power can indicate the negative one. In contrast to our findings, most studies show significantly reduced low-frequency oscillations after acute ketamine treatment $[12,16,47,58,69-73]$, and this discrepancy might be explained by the differences in the applied doses.

As any rodent model of a complex human neuropsychiatric disorder, our model has a number of shortcomings. The heterogeneity of this disease and the overlap in several aspects with other neuropsychiatric diseases, especially autism, further complicates the ability to discern the specificity of a given preclinical model $[60,79,80]$. Although autism and schizophrenia are clearly distinct disorders, they share a significant number of common clinical characteristics, including genetics, epidemiology (e.g., prenatal infection, maternal stress, and perinatal hypoxia), behavioral phenotypes (e.g., impairments in social and cognitive behaviors, communicative function, and stereotyped behaviors), neuroimaging and neurophysiological findings (e.g., interneuron dysfunction or disrupted excitation/inhibition balance) $[1,60,79,81,82]$. Furthermore, hypofunction of $N$-methylD-aspartate receptor (NMDAR) signaling contributes to the pathophysiology of both diseases [83-85]. NMDAR1 hypomorphic mice display both schizophrenia- and autism-like changes in social and cognitive behaviors and in the oscillatory activity $[13,18,32-34]$. Most of the behavioral alterations observed in this new substrain can also be detected in autism [81,86-88], similarly, the observed electrophysiological changes in our model might simulate several alterations detected in both the autism and schizophrenia and may contribute to the abnormal sensory and cognitive performance $[1,3,7-9,46,57,58]$. Especially, the significantly enhanced latency in the P2 responses in the new substrain correlates with human studies involving autistic patients and its animal models without influencing peak amplitude [18,85,89-91]. Since most of the abnormalities overlap in these two disorders, these alterations regarding the EEG oscillations should be accompanied by other more specific signs for relevant diagnosis $[1,17,18,32,46,60,68,74,82,85,90,92,93]$.

\section{Conclusion}

Our substrain was originally developed as a complex model of schizophrenia, and has been extensively investigated as such; however, the results indicated that these rats exhibited several autism-like behavioral and neurophysiological phenotypic alterations. It also highlights the challenge of modeling a complex human behavioral disorder in rodents, since as it was mentioned above, most of these biomarkers are non-specific to these diseases. It can be concluded that this substrain produces long-lasting alterations on ERP and EEG oscillations after juvenile social isolation and subchronic ketamine treatment. These results are partially in agreement with clinical data, which suggests that this model provides a limited representation of disturbances observed in EEG of schizophrenic and/or autistic patients. Although the strengths and weaknesses of this model should be evaluated in the future by molecular biological methods, too, we conclude that our model may provide additional opportunity for the translational research of these neuropsychiatric disorders.

\section{Acknowledgements}

Funding for this study was provided by the Hungarian Research Grant (OTKA, K83810), TÁMOP-4.2.2.B-15/1/KONV-2015-0006 and Hungarian Brain Research Program Grant KTIA_13_NAP-A-I/15. These grants had no further role in study design, in collection, analysis and interpretation of data, in the writing of the report, and in the decision to submit the paper for publication.

The authors wish to thank Robert Averkin and Tamás Nagypál for their participation in electrophysiological setup and recordings, Agnes Tandari for her excellent technical assistance and are grateful to Csilla Keresztes for the linguistic review of the manuscript.

\section{References}

[1] D.C. Rojas, L.B. Wilson, Gamma-band abnormalities as markers of autism spectrum disorders, Biomark. Med. 8 (2014) 353-368.

[2] A.H.C. Wong, H.H.M. Van Tol, Schizophrenia: from phenomenology to neurobiology, Neurosci. Biobehav. Rev. 27 (2003) 269-306.

[3] P.J. Uhlhaas, W. Singer, High-frequency oscillations and the neurobiology of schizophrenia, Dialogues Clin. Neurosci. 15 (2013) 301-313.

[4] L.E. Adler, E. Pachtman, R.D. Franks, M. Pecevich, M.C. Waldo, R. Freedman, Neurophysiological evidence for a defect in neuronal mechanisms involved in sensory gating in schizophrenia, Biol. Psychiatry 17 (1982) 639-654.

[5] D.L. Braff, M.A. Geyer, Sensorimotor gating and schizophrenia: human and animal model studies, Arch. Gen. Psychiatry 47 (1990) 181-188.

[6] D.L. Braff, M.A. Geyer, N.R. Swerdlow, Human studies of prepulse inhibition of startle: normal subjects, patient groups, and pharmacological studies, Psychopharmacology (Berl) 156 (2001) 234-258. 
[7] S.R. Sponheim, B.A. Clementz, W.G. Iacono, M. Beiser, Resting EEG in first-episode and chronic schizophrenia, Psychophysiology 31 (1994) 37-43.

[8] S.R. Sponheim, W.G. Iacono, P.D. Thuras, S.M. Nugent, M. Beiser, Sensitivity and specificity of select biological indices in characterizing psychotic patients and their relatives, Schizophr. Res. 63 (2003) 27-38.

[9] E. Basar, Brain oscillations in neuropsychiatric disease, Dialogues Clin. Neurosci. 15 (2013) 291-300.

[10] J. Chen, B.K. Lipska, D.R. Weinberger, Genetic mouse models of schizophrenia: from hypothesis-based to susceptibility gene-based models, Biol. Psychiatry 59 (2006) 1180-1188.

[11] A. Meyer-Lindenberg, From maps to mechanisms through neuroimaging of schizophrenia, Nature 468 (2010) 194-202.

[12] E.M. Sullivan, P. Timi, L.E. Hong, P. O’Donnell, Reverse translation of clinical electrophysiological biomarkers in behaving rodents under acute and chronic NMDA receptor antagonism, Neuropsychopharmacology 40 (2015) 719-727.

[13] S. Bickel, H.P. Lipp, D. Umbricht, Early auditory sensory processsing deficits in mouse mutants with reduced NMDA receptor function, Neuropsychopharmacology 33 (2008) 1680-1689.

[14] B.V. Broberg, B. Oranje, B.Y. Glenthoj, K. Fejgin, N. Plath, J.F. Bastlund, Assessment of auditory sensory processing in a neurodevelopmental animal model of schizophrenia-gating of auditory-evoked potentials and prepulse inhibition, Behav. Brain Res. 213 (2010) 142-147.

[15] D.W.N. Dissanayake, M. Zachariou, C.A. Marsden, R. Mason, Effects of phencyclidine on auditory gating in the rat hippocampus and the medial prefrontal cortex, Brain Res. 1298 (2009) 153-160.

[16] R.S. Ehrlichman, M.J. Gandal, C.R. Maxwell, M.T. Lazarewicz, L.H. Finkel, D. Contreras, et al., $N$-Methyl-D-aspartic acid receptor antagonist-induced frequency oscillations in mice recreate pattern of electrophysiological deficits in schizophrenia, Neuroscience 158 (2009) 705-712.

[17] V.S. Sohal, F. Zhang, O. Yizhar, K. Deisseroth, Parvalbumin neurons and gamma rhythms enhance cortical circuit performance, Nature 459 (2009) 698-702

[18] M.J. Gandal, J. Sisti, K. Klook, P.I. Ortinski, V. Leitman, Y. Liang, et al, $\mathrm{GABA}_{\mathrm{B}}$-mediated rescue of altered excitatory-inhibitory balance, gamma synchrony and behavioral deficits following constitutive NMDAR-hypofunction, Transl. Psychiatry 2 (2012) e142.

[19] M.T. Lazarewicz, R.S. Ehrlichman, C.R. Maxwell, M.J. Gandal, L.H. Finkel, S.J. Siegel, Ketamine modulates theta and gamma oscillations, J. Cogn. Neurosci. 22 (2010) 1452-1464

[20] J.A. Saunders, M.J. Gandal, S.J. Siegel, NMDA antagonists recreate signal-to-noise ratio and timing perturbations present in schizophrenia, Neurobiol. Dis. 46 (2012) 93-100.

[21] R.E. Featherstone, L.R. Nagy, C.G. Hahn, S.J. Siegel, Juvenile exposure to ketamine causes delayed emergence of EEG abnormalities during adulthood in mice, Drug Alcohol Depend. 134 (2014) 123-127.

[22] Y. Tomimatsu, R. Hibino, H. Ohta, Brown Norway rats, a putative schizophrenia model, show increased electroencephalographic activity at rest and decreased event-related potential amplitude, power, and coherence in the auditory sensory gating paradigm, Schizophr. Res. 166 (2015) 171-177.

[23] A. Ahnaou, S. Nayak, A. Heylen, D. Ashton, Drinkenburg WHIM. Sleep and EEC profile in neonatal hippocampal lesion model of schizophrenia, Physiol. Behav. 92 (2007) 461-467.

[24] J.H. Krystal, L.P. Karper, J.P. Seibyl, G.K. Freeman, R. Delaney, D. Bremner, Subanesthetic effects of the noncompetitive NMDA antagonist, ketamine, in humans: psychotomimetic, perceptual, cognitive, and neuroendocrine responses, Arch. Gen. Psychiatry 51 (1994) 199-214.

[25] D.C. Javitt, K.M. Spencer, G.K. Thaker, G. Winterer, M. Hajos, Neurophysiological biomarkers for drug development in schizophrenia, Nat. Rev. Drug Discov. 7 (2008) 68-83.

[26] J.D. Jentsch, R.H. Roth, The neuropsychopharmacology of phencyclidine: from NMDA receptor hypofunction to the dopamine hypothesis of schizophrenia, Neuropsychopharmacology 20 (1999) 201-225.

[27] A.C. Lahti, M.A. Weiler, B.A. Tamara Michaelidis, A. Parwani, C.A. Tamminga, Effects of ketamine in normal and schizophrenic volunteers, Neuropsychopharmacology 25 (2001) 455-467.

[28] J.M. Stone, P.D. Morrison, L.S. Pilowsky, Review: glutamate and dopamine dysregulation in schizophrenia a synthesis and selective review, J. Psychopharmacol. 21 (2007) 440-452.

[29] A.K. Malhotra, D.A. Pinals, C.M. Adler, I. Elman, A. Clifton, D. Pickar, Ketamine-induced exacerbation of psychotic symptoms and cognitive impairment in neuroleptic-free schizophrenics, Neuropsychopharmacology 17 (1997) 141-150.

[30] A.C. Lahti, H.H. Holcomb, D.R. Medoff, C.A. Tamminga, Ketamine activates psychosis and alters limbic blood flow in schizophrenia, Neuroreport 6 (1995) 869-872.

[31] N.R. Swerdlow, M.A. Geyer, J.M. Shoemaker, G.A. Light, D.L. Braff, K.E. Stevens, et al., Convergence and divergence in the neurochemical regulation of prepulse inhibition of startle and N40 suppression in rats, Neuropsychopharmacology 31 (2006) 506-515.

[32] V.M. Tatard-Leitman, C.R. Jutzeler, J. Suh, J.A. Saunders, E.N. Billingslea, S. Morita, et al., Pyramidal cell selective ablation of $N$-methyl-D-aspartate receptor 1 causes increase in cellular and network excitability, Biol. Psychiatry 77 (2015) 556-568.

[33] G.E. Duncan, S.S. Moy, J.A. Lieberman, B.H. Koller, Typical and atypical antipsychotic drug effects on locomotor hyperactivity and deficits in sensorimotor gating in a genetic model of NMDA receptor hypofunction, Pharmacol. Biochem. Behav. 85 (2006) 481-491.
[34] L.C. Amann, T.B. Halene, R.S. Ehrlichman, S.N. Luminais, N. Ma, T. Abel, et al., Chronic ketamine impairs fear conditioning and produces long-lasting reductions in auditory evoked potentials, Neurobiol. Dis. 35 (2009) 311-317.

[35] Z. Petrovszki, G. Adam, G. Tuboly, G. Kekesi, G. Benedek, S. Keri, et al., Characterization of gene-environment interactions by behavioral profiling of selectively bred rats: the effect of NMDA receptor inhibition and social isolation, Behav. Brain Res. 240 (2013) 134-145.

[36] G. Kekesi, Z. Petrovszki, G. Benedek, G. Horvath, Sex-specific alterations in behavioral and cognitive functions in a three hit animal model of schizophrenia, Behav. Brain Res. 284 (2015) 85-93.

[37] M. Hadamitzky, S. Harich, M. Koch, K. Schwabe, Deficient prepulse inhibition induced by selective breeding of rats can be restored by the dopamine D2 antagonist haloperidol, Behav. Brain Res. 177 (2007) 364-367.

[38] G. Liebsch, A. Montkowski, F. Holsboer, R. Landgraf, Behavioural profiles of two Wistar rat lines selectively bred for high or low anxiety-related behaviour, Behav. Brain Res. 94 (1998) 301-310.

[39] K. Schwabe, F. Freudenberg, M. Koch, Selective breeding of reduced sensorimotor gating in Wistar rats, Behav. Genet. 37 (2007) 706-712.

[40] R.J. Racine, M. Steingart, D.C. McIntyre, Development of kindling-prone and kindling-resistant rats: selective breeding and electrophysiological studies, Epilepsy Res. 35 (1999) 183-195.

[41] G. Tuboly, G. Benedek, G. Horvath, Selective disturbance of pain sensitivity after social isolation, Physiol. Behav. 96 (2009) 18-22.

[42] G. Paxinos, C. Watson, The Rat Brain in Stereotaxic Coordinates, 5 ed., Elsevier Academic Press, Burlington, 2005.

[43] K. Gjini, S. Burroughs, N.N. Boutros, Relevance of attention in auditory sensory gating paradigms in schizophrenia A pilot study, J. Psychophysiol. 25 (2011) 60-66.

[44] L. Witten, B. Oranje, A. Mork, B. Steiniger-Brach, B.Y. Glenthoj, J.F. astlund, Auditory sensory processing deficits in sensory gating and mismatch negativity-like responses in the social isolation rat model of schizophrenia, Behav. Brain Res. 266 (2014) 85-93.

[45] J. Smucny, A. Olincy, L.C. Eichman, E. Lyons, J.R. Tregellas, Early sensory processing deficits predict sensitivity to distraction in schizophrenia, Schizophr. Res. 147 (2013) 196-200.

[46] R.E. Featherstone, M.F. McMullen, K.R. Ward, J. Bang, J. Xiao, S.J. Siegel, EEC biomarkers of target engagement, therapeutic effect, and disease process, Ann. N. Y. Acad. Sci. 1344 (2015) 12-26.

[47] L.E. Hong, A. Summerfelt, R.W. Buchanan, P. O’Donnell, G.K. Thaker, M.A Weiler, et al., Gamma and delta neural oscillations and association with clinical symptoms under subanesthetic ketamine, Neuropsychopharmacology 35 (2010) 632-640.

[48] C.R. Maxwell, R.S. Ehrlichman, Y.L. Liang, D. Trief, S.J. Kanes, J. Karp, et al., Ketamine produces lasting disruptions in encoding of sensory stimuli, J. Pharmacol. Exp. Ther. 316 (2006) 315-324.

[49] C. Siegel, M. Waldo, G. Mizner, L.E. Adler, R. Freedman, Deficits in sensory gating in schizophrenic patients and their relatives: evidence obtained with auditory evoked responses, Arch. Gen. Psychiatry 41 (1984) 607-612.

[50] R. Freedman, L.E. Adler, G.A. Gerhardt, M. Waldo, N. Baker, G.M. Rose, et al., Neurobiological studies of sensory gating in schizophrenia, Schizophr. Bull. 13 (1987) 669-678.

[51] O.M. de Wilde, L.J. Bour, P.M. Dingemans, J.H. Koelman, D.H. Linszen, Failure to find P50 suppression deficits in young first-episode patients with schizophrenia and clinically unaffected siblings, Schizophr. Bull. 33 (2007) 1319-1323.

[52] J.L. Santos, E.M. Sanchez-Morla, A. Aparicio, M.A. Garcia-Jimenez, C. Villanueva, V. Martinez-Vizcaino, et al., P50 gating in deficit and nondeficit schizophrenia, Schizophr. Res. 119 (2010) 183-190.

[53] C.M. Yee, T.J. Williams, P.M. White, K.H. Nuechterlein, D. Ames, K.L. Subotnik, Attentional modulation of the P50 suppression deficit in recent-onset and chronic schizoprenia, J. Abnorm. Psychol. 119 (2010) 31-39.

[54] B. Oranje, C.C. Gispen-de Wied, M.N. Verbaten, R.S. Kahn, Modulating sensory gating in healthy volunteers: the effects of ketamine and haloperidol, Biol. Psychiatry 52 (2002) 887-895.

[55] B.N. van Berckel, B. Oranje, J.M. Van Ree, M.N. Verbaten, R.S. Kahn, The effects of low dose ketamine on sensory gating, neuroendocrine secretion and behavior in healthy human subjects, Psychopharmacology (Berl) 137 (1998) 271-281.

[56] N.M.W.J. de Bruin, B.A. Ellenbroek, A.R. Cools, A.M.L. Coenen, E.L.J.M. van Luijtelaar, Differential effects of ketamine on gating of auditory evoked potentials and prepulse inhibition in rats, Psychopharmacology (Berl) 142 (1999) 9-17.

[57] J.S. Kwon, B.F. O’Donnell, G.V. Wallenstein, R.W. Greene, Y. Hirayasu, P.G. Nestor, Gamma frequency-range abnormalities to auditory stimulation in schizophrenia, Arch. Gen. Psychiatry 56 (1999) 1001-1005.

[58] K.M. Spencer, P.G. Nestor, R. Perlmutter, M.A. Niznikiewicz, M.C. Klump, M. Frumin, Neural synchrony indexes disordered perception and cognition in schizophrenia, Proc. Natl. Acad. Sci. U. S. A. 101 (2004) 17288-17293.

[59] G. Buzsaki, A. Draguhn, Neuronal oscillations in cortical networks, Science 304 (2004) 1926-1929.

[60] E.V. Orekhova, T.A. Stroganova, A.O. Prokofyev, G. Nygren, C. Gillberg, M. Elam, Sensory gating in young children with autism: relation to age, IQ, and EEG gamma oscillations, Neurosci. Lett. 434 (2008) 218-223.

[61] R.D. Traub, M.A. Whittington, E.H. Buhl, J.G. Jefferys, H.J. Faulkner, On the mechanism of the gamma $->$ beta frequency shift in neuronal oscillations 
induced in rat hippocampal slices by tetanic stimulation, J. Neurosci. 19 (1999) 1088-1105.

[62] I. Koychev, W. El-Deredy, T. Mukherjee, C. Haenschel, J.F.W. Deakin, Core dysfunction in schizophrenia: electrophysiology trait biomarkers, Acta Psychiatr. Scand. 126 (2012) 59-71.

[63] M.P. Symond, A.W. Harris, E. Gordon, L.M. Williams, Gamma synchrony in first-episode schizophrenia: a disorder of temporal connectivity, Am. J. Psychiatry 162 (2005) 459-465.

[64] C. Norra, T.D. Waberski, W. Kawohl, H.J. Kunert, D. Hock, R. Gobbele, High-frequency somatosensory thalamocortical oscillations and psychopathology in schizophrenia, Neuropsychobiology 49 (2004) 71-80.

[65] P. Lakatos, C.E. Schroeder, D.I. Leitman, D.C. Javitt, Predictive suppression of cortical excitability and its deficit in schizophrenia, J. Neurosci. 33 (2013) $11692-11702$.

[66] M. Gerez, A. Tello, Selected quantitative EEG (QEEG) and event-related potential (ERP) variables as discriminators for positive and negative schizophrenia, Biol. Psychiatry 38 (1995) 34-49.

[67] L.E. Hong, A. Summerfelt, B.D. Mitchell, R.P. McMahon, I. Wonodi, R.W. Buchanan, et al., Sensory gating endophenotype based on its neural oscillatory pattern and heritability estimate, Arch. Gen. Psychiatry 65 (2008) 1008-1016.

[68] M. Carlen, K. Meletis, J.H. Siegle, J.A. Cardin, K. Futai, D. Vierling-Claassen, et al., A critical role for NMDA receptors in parvalbumin interneurons for gamma rhythm induction and behavior, Mol. Psychiatry 17 (2012) 537-548.

[69] K. Kittelberger, E.E. Hur, S. Sazegar, V. Keshavan, B. Kocsis, Comparison of the effects of acute and chronic administration of ketamine on hippocampal oscillations: relevance for the NMDA receptor hypofunction model of schizophrenia, Brain Struct. Funct. 217 (2012) 395-409.

[70] D. Pinault, $N$-Methyl-D-aspartate receptor antagonists ketamine and MK-801 induce wake-related aberrant gamma oscillations in the rat neocortex, Biol. Psychiatry 63 (2008) 730-735.

[71] T. Kiss, J. Feng, W.E. Hoffmann, C.L. Shaffer, M. Hajos, Rhythmic theta and delta activity of cortical and hippocampal neuronal networks in genetically or pharmacologically induced $N$-methyl-D-aspartate receptor hypofunction under urethane anesthesia, Neuroscience 237 (2013) 255-267.

[72] T. Hiyoshi, D. Kambe, S. Karasawa Ji Chaki, Differential effects of NMDA receptor antagonists at lower and higher doses on basal gamma band oscillation power in rat cortical electroencephalograms, Neuropharmacology 85 (2014) 384-396.

[73] K.G. Phillips, M.C. Cotel, A.P. McCarthy, D.M. Edgar, M. Tricklebank, M.J. O'Neill, et al., Differential effects of NMDA antagonists on high frequency and gamma EEG oscillations in neurodevelopmental model of schizophrenia, Neuropharmacology 62 (2012) 1359-1370.

[74] D. Begic, L. Hotujac, N. Jokic-Begic, Quantitative EEG in 'positive' and 'negative' schizophrenia, Acta Psychiatr. Scand. 101 (2000) 307-311.

[75] O.M. Markand, Alpha rhythms, J. Clin. Neurophysiol. 7 (1990) 163-189.

[76] V. Knott, A. Labelle, B. Jones, C. Mahoney, Quantitative EEG in schizophrenia and in response to acute and chronic clozapine treatment, Schizophr. Res. 50 (2001) 41-53.

[77] G. Winterer, D.R. Weinberger, Genes, dopamine and cortical signal-to-noise ratio in schizophrenia, Trends Neurosci. 27 (2004) 683-690.
[78] J. Lisman, Excitation inhibition, local oscillations, or large-scale loops: what causes the symptoms of schizophrenia, Curr. Opin. Neurobiol. 22 (2012) 537-544.

[79] M.J.C.M. Magnee, B. Oranje, H. van Engeland, R.S. Kahn, C. Kemner, Cross-sensory gating in schizophrenia and autism spectrum disorder: EEG evidence for impaired brain connectivity, Neuropsychologia 47 (2009) $1728-1732$.

[80] R.S. Kahn, I.E. Sommer, The neurobiology and treatment of first-episode schizophrenia, Mol. Psychiatry 20 (2015) 84-97.

[81] J.L. Silverman, M. Yang, C. Lord, J.N. Crawley, Behavioural phenotyping assays for mouse models of autism, Nat. Rev. Neurosci. 11 (7) (2010) 490-502.

[82] R.G. Port, M.J. Gandal, T.P.L. Roberts, S.J. Siegel, G.C. Carlson, Convergence of circuit dysfunction in ASD: a common bridge between diverse genetic and environmental risk factors and common clinical electrophysiology, Front. Cell. Neurosci. 8 (2014) 414

[83] E.-J. Lee, S.Y. Choi, E. Kim, NMDA receptor dysfunction in autism spectrum disorders, Curr. Opin. Pharmacol. 20 (2015) 8-13.

[84] J.H. Krystal, D.C. D’Souza, I.L. Petrakis, A. Belger, R.M. Berman, D.S. Charney, NMDA agonists and antagonists as probes of glutamatergic dysfunction and pharmacotherapies in neuropsychiatric disorders, Harv. Rev. Psychiatry 7 (1999) 125-143.

[85] M.J. Gandal, R.L. Anderson, E.N. Billingslea, G.C. Carlson, T.P.L. Roberts, S.J. Siegel, Mice with reduced NMDA receptor expression: more consistent with autism than schizophrenia, Genes Brain Behav. 11 (2012) 740-750.

[86] E.G. Duerden, M.J. Taylor, M. Lee, P.A. McGrath, K.D. Davis, S.W. Roberts, Decreased sensitivity to thermal stimuli in adolescents with autism spectrum disorder: relation to symptomatology and cognitive ability, J. Pain 16 (2015) 463-471.

[87] W. Perry, A. Minassian, B. Lopez, L. Maron, A. Lincoln, Sensorimotor gating deficits in adults with autism, Biol. Psychiatry 61 (2007) 482-486.

[88] C. Schmitz, P. Rezaie, The neuropathology of autism: where do we stand? Neuropathol. Appl. Neurobiol. 34 (2008) 4-11.

[89] S. Itagaki, H. Yabe, Y. Mori, H. Ishikawa, Y. Takanashi, Si. Niwa, Event-related potentials in patients with adult attention-deficit/hyperactivity disorder versus schizophrenia, Psychiatry Res. 189 (2011) 288-291.

[90] M.J. Gandal, J.C. Edgar, R.S. Ehrlichman, M. Mehta, T.P.L. Roberts, S.J. Siegel, Validating g oscillations and delayed auditory responses as translational biomarkers of autism, Biol. Psychiatry 68 (2010) 1100-1106.

[91] T.P. Roberts, S.Y. Khan, M. Rey, J.F. Monroe, K. Cannon, L. Blaskey, et al., MEG detection of delayed auditory evoked responses in autism spectrum disorders: towards an imaging biomarker for autism, Autism Res. 3 (2010) 8-18.

[92] M. Murias, S.J. Webb, J. Greenson, G. Dawson, Resting state cortical connectivity reflected in EEG coherence in individuals with autism, Biol. Psychiatry 62 (2007) 270-273.

[93] R. Coben, A.R. Clarke, W. Hudspeth, R.J. Barry, EEG power and coherence in autistic spectrum disorder, Clin. Neurophysiol. 119 (2008) 1002-1009. 